\title{
Avaliação da Rede Social Educacional de Novo Hamburgo
}

\author{
Marcelo da Silva dos Santos ${ }^{1}$, Jorge Luis Victória Barbosa ${ }^{2}$, \\ Sandro José Rigo ${ }^{2}$ \\ Prefeitura Municipal de Novo Hamburgo ${ }^{1}$ \\ Universidade do Vale do Rio dos Sinos (UNISINOS) ${ }^{2}$
}

marcelo@novohamburgo.rs.gov.br,jbarbosa@unisinos.br, rigo@unisinos.br

\begin{abstract}
Resumo. Este artigo aborda a Rede Social Educacional do Município de Novo Hamburgo, nomeada como RedEdu. A RedEdu está em desenvolvimento desde o início do ano de 2013, sendo uma ferramenta colaborativa e de socialização para a comunidade da Rede Municipal de Ensino. A rede é baseada em conceitos amplamente difundidos entre os usuários da Internet com o intuito de integrar em um ambiente colaborativo toda a comunidade escolar. $O$ artigo descreve a organização proposta para a RedEdu, suas principais ferramentas e uma avaliação inicial junto ao grupo de usuários. Os resultados mostraram uma resistência na adoção da tecnologia, mas uma abertura para evolução $e$ adoção da RedEdu.
\end{abstract}

Palavras-Chaves: Rede Social Educacional, Colaboração, Socialização.

\begin{abstract}
This article approaches the Educational Social Network created for the city of Novo Hamburgo, called RedEdu. The RedEdu is in development from the beginning of 2013 as a collaborative tool to the community of municipal schools. The network is based on concepts already widespread among Internet users in order to integrate in a collaborative environment throughout the school community. The article describes the organization proposed to RedEdu, its main tools, and the first impact with the users group. The results showed a resistance to technology adoption, but openness to evolution and adoption of RedEdu.
\end{abstract}

Keywords: Social Network Educational, Collaboration, Socialization.

\section{Introdução}

A disseminação do uso de redes sociais virtuais em camadas cada vez mais jovens da sociedade vem tornando-se parte do cotidiano (Guedes, 2013). Conforme pesquisa do IBOPE (2012), dos brasileiros que acessam a Internet, $72 \%$ incorporaram às suas rotinas o hábito de navegar em pelo menos um sítio de rede social online. Além disso, $69,3 \%$ se enquadram na faixa etária entre 16 e 35 anos. A maioria dessas redes tem como único objetivo o entretenimento, fato esse que ocasionou o estigma de causar queda de produtividade. Em termos gerais, uma rede social pode ser caracterizada como uma estrutura composta por pessoas ou organizações, essas ligadas por relacionamentos horizontais e não hierárquicos, onde partilham valores e objetivos comuns (Duarte e Frei, 2008). Uma rede social virtual utiliza sistemas automatizados e a Internet para 
proporcionar esta interação.

O fato de muitos estudantes usarem sítios de redes sociais fez com que professores começassem a se familiarizar com esta tendência para aplicá-la na educação, explorando novas possibilidades para melhoria dos resultados da aprendizagem (Fritzen, Siqueira e Andrade, 2014). Além de disponibilizar os materiais acadêmicos da aula, como textos, slides e exercícios resolvidos, os professores também podem usar o canal para aproximação com os alunos, ajudando o professor a conhecê-los melhor. Assim, sabendo os interesses dos jovens para os quais ministra aulas, ele prepara aulas mais focadas e interessantes, que facilitariam a aprendizagem (Phillips e Baird, 2014).

Alguns acreditam que essas redes sociais com fins educacionais somente se consolidarão em alguns anos, quando também os professores serão desta geração que cresceu vivenciando a experiência de sociabilização virtual, quando estes iniciarão as tarefas e as discussões diretamente na rede.

O presente trabalho descreve os resultados alcançados com a primeira fase de implantação da Rede Social Educativa do Município de Novo Hamburgo, focando a usabilidade da ferramenta e se a qualidade do material didático postado na rede está de acordo com as expectativas do projeto. Além disso, o artigo discute uma avaliação que considerou aspectos quantitativos e qualitativos do funcionamento do ambiente. $\mathrm{O}$ principal objetivo do trabalho descrito nesse artigo é a avaliação da proposta, buscando pesar acertos e erros como base para um processo de aprimoramento e melhoria contínua.

Na seção 2 o artigo apresenta um panorama sobre a utilização de ambientes virtuais no âmbito da educação. Na seção 3 o texto aborda um breve histórico do projeto da RedEdu. A seção 4 descreve a metodologia usada na validação e os resultados obtidos. O capítulo 5 apresenta conclusões e os trabalhos futuros.

\section{Redes Sociais e Educação}

Boyd e Ellinson (2014) definem redes sociais como serviços baseados na Web que permitem aos indivíduos construírem um perfil, público ou semi-público dentro de um sistema limitado, capaz de articular uma lista de outros usuários com quem compartilhar uma conexão.

Barbosa (2010) enfatiza que as redes sociais constituem um espaço, no qual a interação entre as pessoas permite a construção coletiva, transformação e compartilhamento de ideias e Hardagh (2009) afirma serem as redes sociais uma necessidade humana anterior à Internet, e o desejo de estar junto, compartilhar e colaborar é inato do homem. Por ser a Internet uma rede com tantos indivíduos, ela se tornou um ambiente favorável para produção e troca de conhecimentos (Torres, 2009). Para O’Reilly (2005), a nova geração da Internet, denominada Web 2.0 é caracterizada como um conjunto de tendências socioeconômicas e tecnológicas que serve de base para uma geração de Internet mais madura, baseada na colaboração. Dentre todas as tecnologias que contribuíram para o crescimento da Web 2.0, os sites de redes sociais tiveram maior influência. Sites como Facebook, YouTube, Twitter e Myspace atraem milhares de pessoas devido à possibilidade de conectar pessoas com interesses comuns e interagir com pessoas de todo o mundo (Phillips e Baird, 2014).

Segundo levantamento feito nos últimos anos pela Cetic.br (2012), 95\% dos professores usam a Internet para pesquisas e 91\% para enviar e-mails. Outra informação é que $70 \%$ deles não apresentam qualquer dificuldade para acessar redes sociais. Apesar 
do uso da web, o desafio é fazer com que os docentes realmente se apropriem dessas ferramentas. Por exemplo, no estudo 95\% dos educadores disseram não usar tecnologias para avaliar tarefas de casa. Ainda $86 \%$ dos professores não usam recursos tecnológicos no apoio individual dos alunos. A pesquisa mostra ainda que $55 \%$ dos professores têm resistência ao uso de tecnologias na Educação.

Existem diversos exemplos de sítios de redes sociais usados por professores e alunos como provedores de comunicação (Mora-Soto, 2009) (Mansur, Carvalho e Biazus, 2011) (Dotta, 2111) (Wang, 2011). Além de entreter, as redes podem se tornar ferramentas de interação valiosas no dia a dia do trabalho em sala de aula, quando direcionadas para a complementação dos conteúdos trabalhados presencialmente.

\section{Rede Municipal de Ensino de Novo Hamburgo}

Em 2013 iniciou-se um projeto no município de Novo Hamburgo para criação de uma rede social voltada para fins educacionais. Atualmente, a Rede Municipal de Ensino conta com laboratórios de informática educacional em quase a totalidade das escolas além de participar do projeto "Um Computador por Aluno" (UCA), o que proporcionou a entrega de um notebook para cada aluno da Rede. Buscando a ampliação da inclusão tecnológica, determinou-se que seria relevante o aumento da interação da comunidade escolar. Assim surgiu o interesse no desenvolvimento de uma rede social fechada para membros da comunidade escolar, incluindo docentes, discentes, pais e funcionários. O objetivo seria proporcionar um espaço para interação da comunidade escolar, focando na evolução dos processos de aprendizagem.

Em um primeiro momento uma equipe formada por desenvolvedores e analistas da Secretaria de Tecnologia da Informação e Inclusão Digital, junto a gestores e professores da Secretaria da Educação do Município, realizou a modelagem da rede social. Após esse processo identificaram-se as ferramentas e tecnologias que seriam empregadas para sua construção.

A fase de implantação e avaliação foi iniciada em meados de agosto de 2013, sendo que para sua validação foi selecionado um grupo de 20 docentes para testar as funcionalidades. Em menos de uma semana, sem nenhuma divulgação oficial o grupo já passava de 70 usuários cadastrados. A rede está atualmente em funcionamento com um projeto-piloto, envolvendo somente os docentes do Município, tendo aproximadamente 750 usuários cadastrados.

O ambiente batizado como RedEdu foi baseado em estruturas amplamente difundidas entre os usuários da Internet. Conceitos como "adicionar”, “curtir”, "seguir e ser seguido" foram incorporados com o intuito de facilitar sua difusão. As partes principais da ferramenta são as seguintes:

- Página inicial: Ao entrar na rede o visitante visualiza a "página inicial”. Ela contém seu feed de notícias públicas e uma agenda de eventos, que consiste em informações e eventos de interesse a toda comunidade escolar. Depois de efetuada a autenticação, a página inicial passa a ser exclusivamente sua e todos os blocos passam a mostrar também os eventos e notícias particulares ou relacionados aos grupos que aquela pessoa é integrante. Um exemplo de página inicial pode ser visto na Figura 1. 


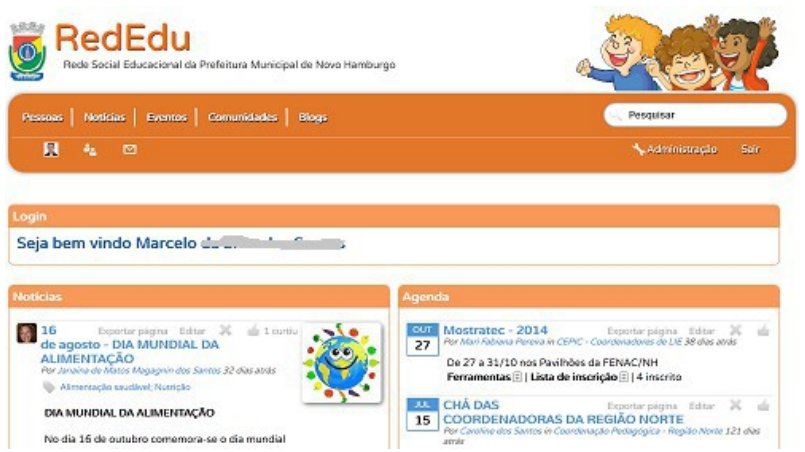

Figura 1: Tela inicial da RedEdu

- Perfil: Na primeira autenticação o visitante será solicitado a criar um perfil com informações profissionais como email institucional, setor ou escola onde está atuando e formação acadêmica. Também nesta visão, alguns módulos estão disponíveis, como feed de notícias do portal da Educação, agenda, um bloco com links para os sistemas utilizados pelo município, amigos, filtro de busca de participantes por escolas e um mural de recados (Figura 2).

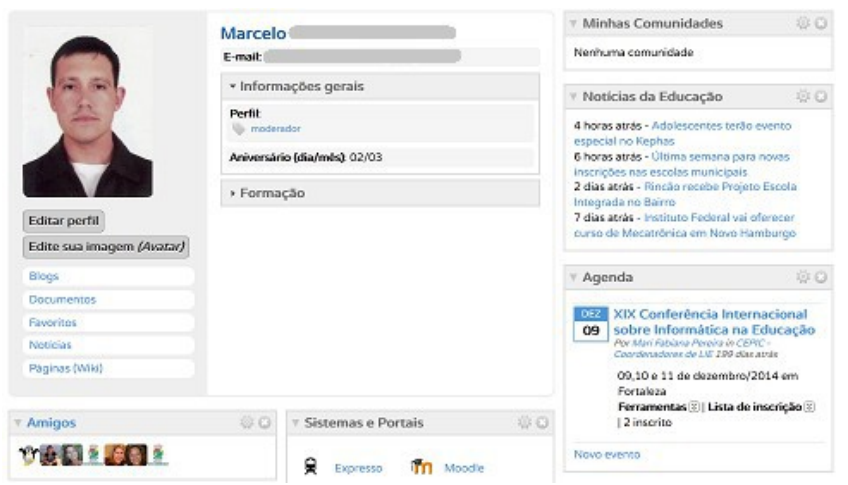

Figura 2: Perfil dos usuários.

- Comunidades: As comunidades são espaços online onde os participantes podem interagir e compartilhar. Essa é uma excelente maneira dos professores trabalharem em projetos de colaboração. As Comunidades têm suas próprias ferramentas, blogs, agenda, listas de discussão, páginas colaborativas e um espaço para publicação de documentos. Uma listagem de comunidades criadas pode ser vista na Figura 3.

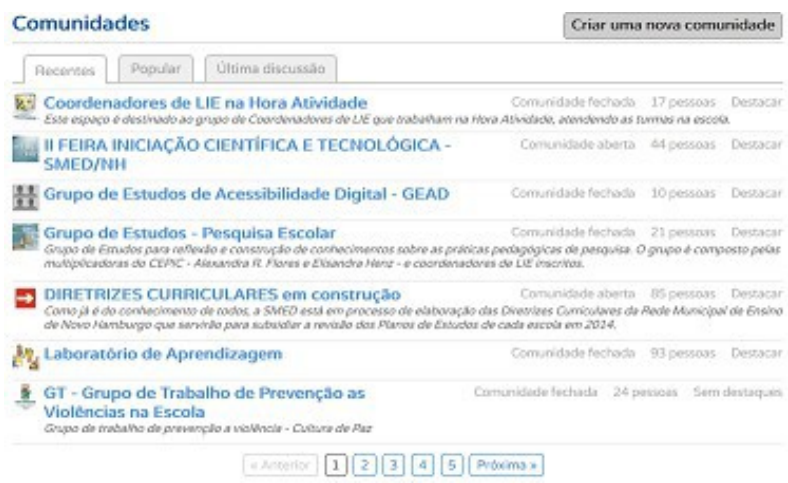

Figura 3: Listagem de comunidades abertas 


\section{Avaliação da RedEdu}

A avaliação seguiu duas abordagens. A primeira focando quantitativamente os números de acesso ao ambiente através das estatísticas geradas pela utilização. A segunda foi uma abordagem qualitativa através de aplicação de questionário junto aos usuários.

A primeira avaliação foi executada por meio do uso de ferramentas digitais para mensuração do conteúdo produzido e volume de interações nos conteúdos propostos. A segunda focou em um nível de realidade que não pode ser quantificado, trabalhando com o universo de significados, das ações, motivos, crenças, aspirações, valores, atitudes e relações humanas, captadas a partir do olhar dos pesquisadores, ou seja, preocupa-se principalmente em compreender e explicar a dinâmica das relações sociais (Minayo, 2007). O questionário foi direcionado para investigar aspectos como usabilidade, confiabilidade, atendimento as expectativas, pontos negativos e positivos, dentre outras questões.

\subsection{Avaliação Quantitativa}

Para obtenção das métricas de acesso e trafego no ambiente foram extraídas estatísticas com auxílio da ferramenta Google Analytics (2013). Os dados começaram a ser armazenados em janeiro de 2013, quando se iniciou o experimento com um grupo de cinco usuários, entre desenvolvedores, analistas e gerência da Secretaria da Educação. Em 1 de fevereiro de 2013 foi convidado a conhecer a ferramenta um grupo de docentes para que pudesse ser iniciado o projeto-piloto. Em 15 de agosto do mesmo ano chegouse aos 300 usuários sem qualquer divulgação oficial, visto que o grupo que foi convidado a testar não passava de 30 pessoas. Em 2014 este número elevou para 750 usuários e aumenta constantemente.

Em 29 de março de 2013 foi registrado um pico de acessos de 10.967 visualizações de páginas em um único dia, com um tempo médio de 2 minutos e 10 segundos por visita. Esse pico de acesso se manteve até a última medição realizada em 30 de maio de 2014.

Referente ao comportamento dos usuários seguem números obtidos no período entre 1 de fevereiro e 30 de maio de 2014:

- a rede conta com uma média de 750 usuários cadastrados, destes apenas 243 usuários acessaram mais de uma vez o ambiente e destes, menos de $25 \%$ contribuíram de alguma forma (textos, debates, entre outras formas) para a rede, número este que se elevou para 38\% em nova leitura dois meses depois;

Referente à produção de conteúdo no ambiente no mesmo período, destacam-se alguns aspectos:

- ocorreu a criação e debates em 33 comunidades focadas nos grupos de trabalho e escolas;

- destas comunidades, notou-se que 11 foram comunidades de escolas, envolvendo exclusivamente seus colaboradores;

- quanto às páginas colaborativas, existiram 262 produções em andamento;

- notou-se um volume de 104 arquivos armazenados no ambiente (texto, imagens e outros formatos);

- quanto aos blogs se verificou 58 publicações com participação ativa;

- chegou a 2411 o número de mensagens trocadas entre os participantes; 
- foram registrados 36 eventos entre congressos, palestras ou cursos de formação;

- foram publicadas 17 notícias referentes a congressos, cursos e assuntos de interesse municipal.

Os dados demonstraram que a plataforma serviu apenas com o objetivo de efetuar leituras rápidas de comunicados e consulta aos sistemas da instituição.

\subsection{Pesquisa Qualitativa}

A segunda estratégia de avaliação foi convidar os docentes participantes do piloto a responderem um formulário de pesquisa com o intuito de conhecer as impressões dos colaboradores no uso da ferramenta. Nesse questionário buscou-se verificar aspectos tanto da ferramenta, como usabilidade, acessibilidade e navegabilidade, como suas expectativas, uso da interface e visão de futuros trabalhos aplicando os recursos apresentados. A pesquisa esteve disponível no próprio ambiente durante os meses de abril e maio de 2014. Do total de usuários cadastrados obteve-se 41 respostas ao questionário.

As três primeiras questões abordam a interface da ferramenta avaliando as características de usabilidade, navegabilidade e acessibilidade. Para embasar a avaliação foram aplicados os conceitos de Nielsen (2014), apresentando a cada questão os parâmetros de avaliação e a definição de cada quesito. A Tabela 1 apresenta as questões, conforme as definições de Nielsen. Os resultados estão expressos nas Figuras 4, 5 e 6.

Tabela 1. Primeiras três questões apresentadas aos avaliadores

\begin{tabular}{|c|c|}
\hline Item avaliado & Questão apresentada \\
\hline Usabilidade & $\begin{array}{l}\text { Usabilidade é a facilidade com que as pessoas podem empregar uma ferramenta } \\
\text { ou objeto a fim de realizar uma tarefa específica e importante. Levando em } \\
\text { consideração os pesos } 1 \text { - PÉSSIMO, } 2 \text { - RUIM, } 3 \text { - REGULAR, } 4 \text { - BOM e } 5 \\
\text { - ÓTIMO, selecione o seu grau de satisfação quanto a Usabilidade do ambiente. }\end{array}$ \\
\hline Navegabilidade & $\begin{array}{l}\text { Navegabilidade é propriedade ou capacidade da interface de um portal na } \\
\text { Internet de facilitar ao usuário chegar ao conteúdo buscado da maneira mais } \\
\text { eficiente possível. Levando em consideração os pesos } 1 \text { - PÉSSIMO, } 2 \text { - } \\
\text { RUIM, } 3 \text { - REGULAR, } 4 \text { - BOM e 5- ÓTIMO, selecione o seu grau de } \\
\text { satisfação quanto a Navegabilidade do ambiente. }\end{array}$ \\
\hline Acessibilidade & $\begin{array}{l}\text { Acessibilidade refere-se à prática inclusiva de fazer websites que possam ser } \\
\text { utilizados por todas as pessoas que tenham deficiência ou não, seja ela visual, } \\
\text { cognitiva ou motora. Quando os sites são corretamente concebidos, } \\
\text { desenvolvidos e editados, todos os usuários podem ter igual acesso à } \\
\text { informação e funcionalidades. Levando em consideração os pesos } 1 \text { - } \\
\text { PÉSSIMO, } 2 \text { - RUIM, } 3 \text { - REGULAR, } 4 \text { - BOM e 5- ÓTIMO, selecione o seu } \\
\text { grau de satisfação quanto a Usabilidade do ambiente. }\end{array}$ \\
\hline
\end{tabular}

A quarta questão versou sobre as ferramentas internas ao ambiente como blogs, wiki's, agenda de eventos, chat, comunidades e troca de mensagens. Solicitou-se que o usuário determinasse para cada uma das funcionalidades a frequência com a qual utilizava o recurso, atribuindo um conceito que variava entre "MUITO RARAMENTE" e "MUITO FREQUENTEMENTE”. Os resultados são expressos nos gráficos da Figura 7. 


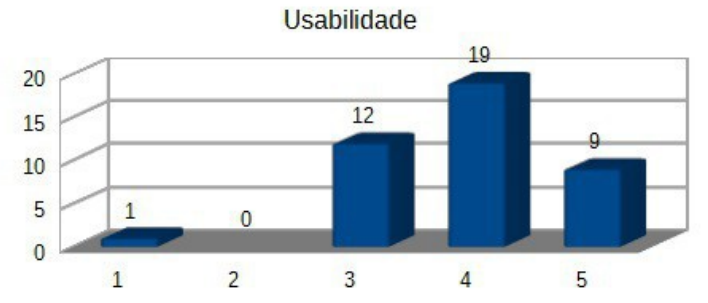

Figura 4. Avaliação da usabilidade
Navegabilidade

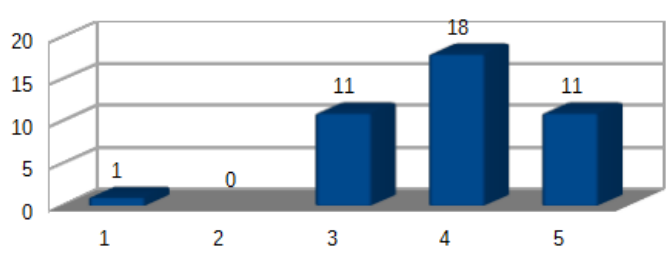

Figura 5. Avaliação da

navegabilidade

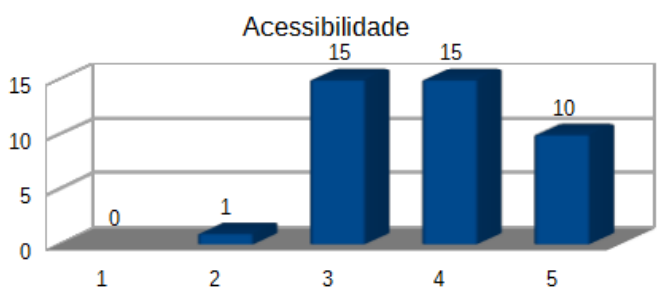

Figura 6. Avaliação da acessibilidade

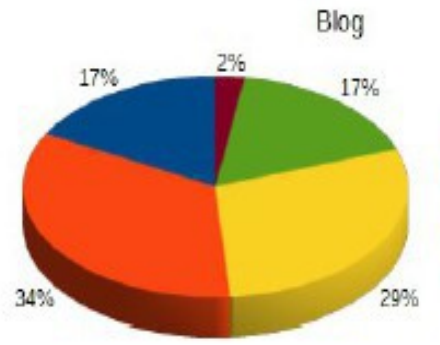

Comunidades

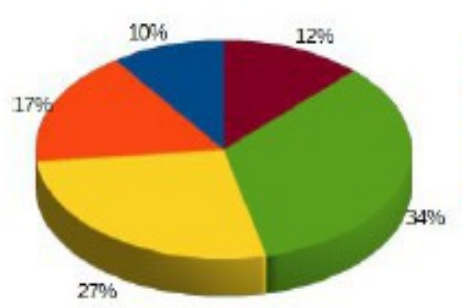

Envio de Mensagens

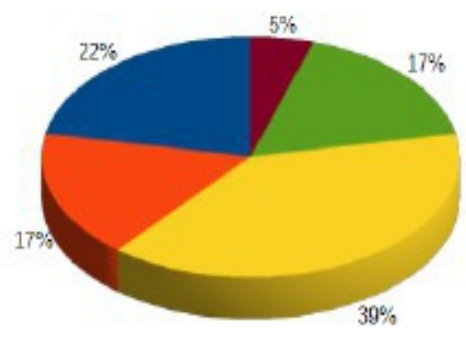

- Muto raramente

- Raramente

Aazozusimerts

in Frequertemerts

- Muto frequartemerte

- Raramente

- Razoavalmente

- Frequentemente

- Muito frequentemente

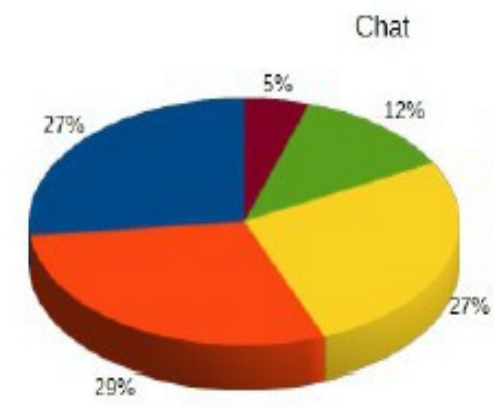

Eventos

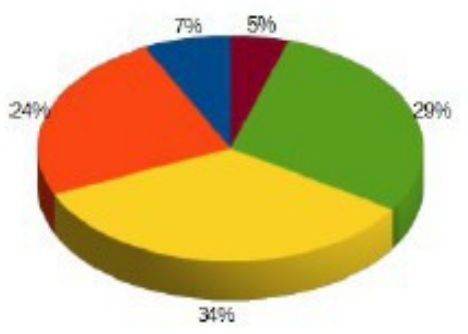

Wiki

Muito raramente - Raramente

enazoavelments - Frequentemente

- Muito frequentemente

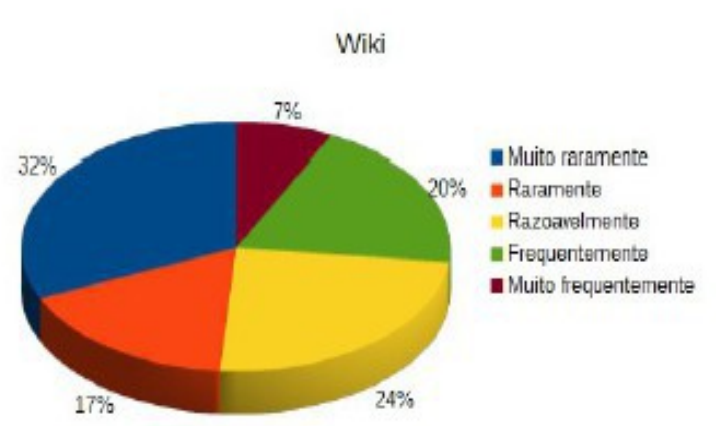

- Muito raramente

- Raramente

in Razoavelmente

n Frequentemente

- Muito frequentemente

Figura 7. Frequência de utilização das principais ferramentas

V. $12 \mathrm{~N}^{\mathrm{o}}$ 2, dezembro, 2014 
Avaliando a qualidade do conteúdo produzido, notou-se um grande número de páginas pessoais, assuntos diversos e nem sempre focados em educação. Uma leitura anterior realizada no ano de 2013 mostrava que o tempo disponibilizado a navegação

pelo ambiente em média não passava de 2 minutos e que as áreas visitadas nessas visitas rápidas foram a caixa de mensagens e o mural de notícias. Passados seis meses de uso verificou-se que as últimas comunidades abertas para discussão, foram de temas como grupos de estudos em projetos para educação quanto a abordagens sobre drogas e outros ilícitos, projetos interdisciplinares entre diferentes anos ou diferentes escolas. Isso demonstrou a implantação de ideias capturadas na rede e foram expandidas para outras escolas, apresentando ganhos de agilidade por colaboração virtual e melhora na integração da Rede Municipal de Ensino.

Também foram apresentadas duas questões dissertativas aos avaliadores: "Quais suas primeiras impressões quanto ao ambiente?" e "Qual sua expectativa para o futuro do ambiente?”. Avaliando as respostas notou-se que $80 \%$ dos docentes acreditam que a proposta beneficie o cotidiano do professor, não só aumentando a rede de disseminação de conhecimento e colaboração, mas como ferramenta para implantação e gerenciamento de projetos multidisciplinares.

Outras respostas mostraram impressões positivas também quanto à aparência do ambiente e a aplicação dos recursos para colaboração entre docentes que podem trocar experiências e dinâmicas para aplicar no aprendizado em sala de aula. Em contraponto, um pequeno número apontou que não vislumbrava a utilidade para auxilio das praticas escolares e afirmou ter pouca segurança em trabalhar com recursos digitais. Outros relataram medo de que alguma ideia exposta e mal compreendida pudesse causar qualquer mal-estar na equipe. Os mesmos, responderam que utilizam ferramentas sociais de lazer todos os dias, porém não tem interesse em usar um ambiente virtual com foco profissional para a troca de material e ideias fora do horário de trabalho.

Quanto ao uso do ambiente, a avaliação dos resultados da pesquisa qualitativa mostrou que quase a totalidade dos entrevistados sentiu-se a vontade no ambiente, muitos relatando a proximidade da interface com outros ambientes recreativos e de lazer que utilizam no seu cotidiano. Ainda assim, muitos relataram a sensação e descontentamento com "mais uma coisa" para que os docentes tenham que se preocupar, já que não possuem tempo hábil durante o período de aulas e já que é um ambiente para uso profissional, relataram não ter intenção de dispor o tempo que eles têm para elaboração dos conteúdos programáticos para utilizar a ferramenta.

\section{Considerações finais}

Com a influência da Web sobre todas as facetas da vida contemporânea, vidas virtual e real estão cada vez mais se integrando, criando novas oportunidades para os alunos adquirirem conhecimento e compartilharem informações.

A avaliação discutida nesse artigo mostrou uma perspectiva positiva sobre a proposta, mostrando contentamento e facilidade no uso das ferramentas disponibilizadas aos docentes mesmo sendo tímidas as contribuições à produção de conteúdo, mas, ainda assim, dentro de uma faixa esperada nesse período de adaptação.

Existiram casos relatados de projetos que nasceram no ambiente e foram implantados nas escolas, como o caso de grupos de estudos em projetos para educação sobre drogas e outros ilícitos. Isso demonstrou a viabilidade de implantação de ideias provenientes dos debates virtuais e que podem ser estendidas para o mundo real, V. $12 \mathrm{~N}^{\circ}$ 2, dezembro, 2014 
apresentando ganhos de agilidade pela colaboração virtual e consequente melhora na integração da Rede Municipal de Ensino.

Notou-se durante as entrevistas que muitos docentes não possuem intimidade com

tecnologias digitais ou ambientes sociais virtuais, o que causa resistência na adoção da tecnologia nas práticas escolares. Uma estratégia seria a produção de oficinas e painéis de discussão com o os docentes antes do lançamento oficial como forma de disseminar o objetivo do projeto e as possibilidades com o uso do ambiente. Um dos pontos de destaque foi que quase a totalidade do grupo que se mostrou distante e avesso ao uso do ambiente, também relatou não ter recebido informações iniciais sobre os objetivos do projeto e seu foco nas práticas escolares, vendo então o ambiente somente como uma rede social comum. Isso reforça a necessidade destas oficinas com efeito de redução na demora em assimilar os recursos disponíveis e os ganhos para o seu dia a dia. Assim também é possível diminuir o estigma de ser apenas mais uma carga de trabalho a ser somada a todos os afazeres do docente.

Como trabalhos futuros, planeja-se a abertura do ambiente para todos os docentes da Rede Municipal de Ensino. Ainda não há previsão de início para esta etapa, mas acredita-se em efetuar este lançamento ainda no primeiro semestre de 2015. Nota-se que as produções nos últimos meses estão tendo conteúdo cada vez mais relevante, chamando a atenção dos usuários que não estavam sendo assíduos. Portanto acredita-se no futuro da rede como ferramenta útil para os participantes. Pretende-se também aplicar técnicas de gerenciamento (Wagner, Barbosa e Barbosa, 2014) para atualização automática dos perfis dos usuários, os quais atualmente são preenchidos manualmente e permanecem estáticos a menos que sejam atualizados pelos usuários.

O ponto mais relevante que os professores devem ter ciência a respeito da mídia social é que ela está mudando a maneira como nos comunicamos e estimulando uma forma inédita de interação. Os professores precisam conhecer e entender essa tecnologia para que sejam capazes de atender às necessidades educacionais dos alunos de hoje, descobrindo como ensinar e estimular seus alunos a serem bons “cidadãos digitais".

\section{Referências Bibliográficas}

BARBOSA, A. et al. Redes sociais: revolução cultural na internet. Comitê Gestor da Internet no Brasil - CGI, São Paulo, 2010.

BOYD, D. M.; ELLISON, N. B. Social Network Sites: Definition, History, and Scholarship. Journal of Computer-Mediated Communication. Disponível em: <http://jcmc.indiana.edu/vol13/issue1/boyd.ellison.html>. Acesso em: mar. 2014.

CETIC-BR. Tecnologias da Informação e Comunicação para Educação: Pesquisa sobre o Uso das Tecnologias da Informação e da Comunicação no Brasil. Disponível em: <http://www.cetic.br/educacao/2012/>. Acesso em: mar 2014.

DOTTA, S. Uso de uma Mídia Social como Ambiente Virtual de Aprendizagem. In XXII SIMPÓSIO BRASILEIRO DE INFORMÁTICA NA EDUCAÇÃO (SBIE), Aracaju, 2011. p.610-619

DUARTE, Fábio; FREI, Klaus. Redes Urbanas. Redes Urbanas. In: Duarte, Fábio; Quandt, Carlos; Souza, Queila. O Tempo Das Redes, 2008. p.156

FRITZEN, E.; SIQUEIRA, S. W. M.; ANDRADE, L. C. V. Busca Contextualizada Enriquecida com Dados Abertos para Apoiar a Aprendizagem Colaborativa em Redes Sociais. Revista Brasileira de Informática na Educação, [S.l.], v. 21, n. 03, 
p. 25, mar. 2014. ISSN 1414-5685.

GOOGLE ANALITICS. Gráficos de acesso e utilização. Disponível em: $<$ https://accounts.google.com/>. Acesso em: 01 set. 2013.

GUEDES, Taís Morais. As Redes Sociais — Facebook e Twitter - e suas influências nos Movimentos Sociais. Monografia de especialização. Universidade de Brasília. Brasília, 2013.

HARDAGH, C. C. Redes Sociais Virtuais: Uma proposta de escola expandida. 2009. Tese (Doutorado em Educação) - Universidade Católica de São Paulo, 2009. 157p.

IBOPE Mídia. Brasileiros caem na rede social. 2012. Disponível em: $<$ http://www.ibope.com.br/pt-br/noticias/Paginas/Brasileiros_caem_na_rede_social.aspx>. Acesso em: jul. 2013.

MANSUR, A.F.U.; CARVALHO, R.A.D.; BIAZUS, M.C.V. Rede de Saberes Coletivos (RESA): Um Ambiente Complexo para Aprendizagem Acadêmica por Meio de Redes Sociais. In: XXII SIMPÓSIO BRASILEIRO DE INFORMÁTICA NA EDUCAÇÃO (SBIE), Aracaju, 2011. p1284 - 1293

MINAYO, M.C.S. O desafio do conhecimento: Pesquisa qualitativa em saúde. 10.ed. São Paulo, 2007.

MORA-SOTO, A. Collaborative Learning Experiences Using Social Networks. In: PROCEEDINGS OF INTERNATIONAL CONFERENCE ON EDUCATION AND NEW LEARNING TECHNOLOGIES, Barcelona, 2009. p.4260-4270

NIELSEN, Jakob. Usability 101: Introduction to usability. Disponível em: <http://www.useit.com/alertbox/20030825.html>. Acesso em: 02 maio de 2014.

O'REILLY, Tim. What is web 2.0. Set. 2005. Disponível em: <http://www.oreillynet.com/pub/a/oreilly/tim/news/2005/09/30/what-is-web20.html>. Acesso em: Mar 2014.

PHILLIPS, Linda Fogg, BAIRD, Derek, et.al. Facebook para Educadores. Disponível em: <www.sead.ufscar.br/outros/FacebookparaEducadores>. Acesso em: 02 ago. 2014.

TORRES, C. A Bíblia do marketing digital: Tudo o que você queria saber sobre marketing e publicidade na Internet e não tinha a quem perguntar. São Paulo, 2009.

WAGNER, A.; BARBOSA, J.L.V.; BARBOSA, D.N.F. A Model for Profile Management applied to Ubiquitous Learning environments. Expert System with Application, v.41, n.4, 2014. p. 2023-2034

WANG, Q.; et.el. Using the Facebook group as a learning management system: An exploratory study. British Journal of Educational Technology, 2011. 43(3):428438 doi:10.1111/j.1467-8535.2011.01195.x 